\title{
PRINCIPALES LÍNEAS SOBRE LA PERSONA JURÍDICA EN EL CÓDIGO CIVIL Y COMERCIAL
}

\author{
FRANCISCO A. JUNYENT BAS \\ UNIVERSIDAD NACIONAL DE CÓRDOBA
}

ARGENTINA.

"El secreto para el cambio es enfocar toda la energía, no luchando contra lo viejo, sino, construyendo lo nuevo".

Sócrates. 


\section{INTRODUCCIÓN}

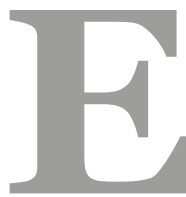

1 Código de Vélez receptó una teoría general de las personas físicas y jurídicas cuando estableció en el art. 30 que: "son personas todos los entes susceptibles de adquirir derechos y contraer obligaciones".

A su vez, el art. 31 de dicho cuerpo legal sigue el sistema "binario" al señalar que las personas son: "de existencia ideal o de existencia visible".

Igualmente, el art. 32 conceptualizó por exclusión a las personas de existencia ideal, y en el art. 51, a las personas de existencia física.

El nuevo Código Civil y Comercial (CCC) pareciera apartarse de esta teoría general, sin perjuicio de lo cual, cabe aclarar que una correcta articulación del art. 19 y siguientes, que regulan la "persona humana", como así también del art. 141, referido a la persona jurídica, permite afirmar que el término "persona" sigue siendo una "categoría jurídica", más allá de que por obvias razones el hombre es anterior al derecho, y consecuentemente, éste último es siempre instrumental y no podría desconocerse, como en otras épocas, el carácter de persona del ser humano.

En los "Fundamentos" del Anteproyecto, la Comisión redactora nada dice en este aspecto, pero cabe afirmar que la nueva compilación sigue respetando el sistema "binario" al reglar por un lado, lo que ahora se denomina "persona humana”, y por el otro, a la "jurídica".

\section{LA PERSONA JURÍDICA}

El CCC precisa el concepto de persona jurídica en el art. 141, al definir que: "Son personas jurídicas todos los entes a los cuales el ordenamiento jurídico les confiere aptitud para adquirir derechos y contraer obligaciones para el cumplimiento de su objeto y los fines de su creación”.

Así, esta noción alude a "todos los entes a los cuales el ordenamiento jurídico les confiere aptitud para adquirir derechos y contraer obligaciones”, lo que permite distinguirla de la persona humana, pues ésta es preexistente al ordenamiento legal, y cualquier limitación a su capacidad constituye una excepción. Lo contrario sucede con las personas jurídicas, a las que la aptitud que se les confiere para adquirir derechos y contraer obligaciones parece limitada al cumplimiento de su objeto y los fines de su creación ${ }^{1}$.

En este sentido, Vítolo puntualiza que ésta "limitación" que refiere a que la capacidad de la persona jurídica está enderezada a su objeto y a los fines de su creación, constituye el 
principio de "especialidad".

El tema tiene su complejidad pues, cabe afirmar que la personalidad que ostentan las personas jurídicas es plena y, en rigor, puede realizar todo tipo de acto sin limitaciones de ninguna especie.

Por ello, la actuación en el ámbito de su objeto y fines de la creación no es un tema que afecte la capacidad del ente, sino que hace la imputabilidad de los actos.

\section{EL COMIENZO DE LA EXISTENCIA DE LA PERSONA JURÍDICA}

El nuevo ordenamiento se mantiene en la doctrina clásica, al reconocer la fuerza del acuerdo de voluntades para la creación de la persona jurídica.

Así, el art. 142 señala que: "La existencia de la persona jurídica privada comienza desde su constitución. No necesita autorización legal para funcionar, excepto disposición legal en contrario. En los casos en que se requiere autorización estatal, la persona jurídica no puede funcionar antes de obtenerla".

Los redactores del Anteproyecto de CCC manifiestan en los Fundamentos que la fuerza jurígena de la voluntad en la creación de las personas jurídicas privadas -dentro del marco de las formas admitidas- lleva a adoptar como principio que, excepto disposición en contrario, la personalidad jurídica nace con el acuerdo de voluntades.

\section{LA COORDINACIÓN CON EL RÉGIMEN SOCIETARIO}

El nuevo régimen, es decir, la reforma del art. 1 de la ley de Sociedades, mantiene el principio que la sociedad nace por el acuerdo de las partes, o por la declaración unilateral del único socio en el caso de la sociedad unipersonal.

Ahora bien, en el supuesto de la sociedad corresponde clarificar que el socio o los socios se organizan mediante la suscripción e integración de aportes a los fines de aplicarlos a la producción o intercambio de bienes o servicios.

En una palabra, en el caso de la sociedad, se articula no sólo el nacimiento de un sujeto de derecho, con el alcance fijado en el art. 2 de la ley especial, sino que se tituliza una empresa.

En efecto, se trata de que el patrimonio aportado se organiza para la producción e intercambio de bienes, aspecto típico de las sociedades comerciales, aun cuando hoy la ley hable de "sociedades en general". 
Dicho derechamente, la sociedad es la titular típica de todo tipo de empresa, y de allí la realidad de una actividad económica organizada propia del derecho comercial, que no puede ignorarse.

Por el contrario, en otro tipo de persona jurídica el fenómeno asociativo no necesariamente organiza una empresa, sino que se trata de tareas de colaboración a los fines de realizar actividades sociales o sin fines de lucro, que no necesariamente implican la existencia de una empresa.

Esta distinción resulta dirimente cuando se realiza el análisis de los distintos tipos de personas jurídicas privadas.

\section{LA PERSONALIDAD DIFERENCIADA}

Una cuestión importante resulta la distinción que la ley realiza respecto de la persona jurídica y sus socios o asociados, según el caso. Así, el art. 143 del CCC dispone: "La persona jurídica tiene una personalidad distinta de la de sus miembros. Los miembros no responden por las obligaciones de la persona jurídica, excepto en los supuestos que expresamente se prevén en este Título y lo que disponga la ley especial".

De tal modo, cuando hablamos de persona jurídica hacemos referencia a un ente distinto a los socios con capacidad jurídica plena para adquirir compromisos propios frente a los terceros y, por ello, determina un centro de imputación diferenciada diverso del patrimonio de los socios. La existencia de una persona jurídica hace necesario considerar la existencia de relaciones internas y externas.

\section{UNA ALTERNATIVA DE ABUSO DE LA PERSONALIDAD: LA INOPONIBILIDAD DE LA PERSONA JURÍDICA}

Los autores del nuevo código también han incorporado a la parte general de la persona jurídica, la figura de la desestimación de la personalidad que fuera reglada en la LS mediante la ley $\mathrm{N}^{0}$ 22.917, en el art. 54 ter, y que fuera motivo de numerosos abordajes doctrinarios y jurisprudenciales.

En esta línea, el legislador ha considerado que el "abuso de la persona jurídica”, como conducta reprochable que desvía los fines de su constitución, merece convertirse en una directiva general, cuestión altamente opinable.

Así, esta figura se encuentra reglada en el art. 144 que estipula: "La actuación que esté destinada a la consecución de fines ajenos a la persona jurídica, constituye un recurso para violar 
la ley, el orden público o la buena fe o para frustrar derechos de cualquier persona, se imputa a quienes a título de socios, asociados, miembros o controlantes directos o indirectos, la hicieron posible, quienes responderán solidaria e ilimitadamente por los perjuicios causados.

Lo dispuesto se aplica sin afectar los derechos de los terceros de buena fe y sin perjuicio de las responsabilidades personales de que puedan ser pasibles los participantes en los hechos por los perjuicios causados".

En consecuencia, las notas que hacen procedente la inoponibilidad de la personalidad jurídica son las siguientes:

a) La constitución o actuación destinada a la consecución de fines ajenos a la persona jurídica, y/o

b) Que constituyan un recurso para violar la ley, el orden público o la buena fe, o para frustrar derechos de cualquier persona.

La configuración de dichas conductas permite "imputar" directamente la responsabilidad a los socios, miembros, asociados y controlantes directos e indirectos que la hicieron posible.

Además, la norma establece que dicha imputación implica responsabilidad solidaria e ilimitada por los perjuicios causados, legitimando a los terceros que hayan resultado afectados a iniciar la respectiva acción de desestimación de la personalidad y consiguiente responsabilidad de quienes hayan abusado del ente.

\section{LA CLASIFICACIÓN DE PERSONAS JURÍDICAS}

Desde esta atalaya, las personas jurídicas pueden clasificarse de diverso modo, y el art. 145 del CCC señala que pueden ser públicas o privadas, absteniéndose de definirlas y haciendo una enumeración de las de carácter público en el artículo 146 y de las de carácter privado en el 148.

El origen de la clasificación se encuentra en el art. 33 del C.C. que reza: "las personas jurídicas pueden ser de carácter público o privado” y se reitera en el art. 141 del Proyecto de 1998. La división fue introducida por la reforma de la Ley 17.711 y no corresponde con la primitiva del Código Civil. Vélez Sársfield en el texto original del art. 33 del C. Civil, siguiendo a Freitas en su Esboço, clasificó a las personas jurídicas en personas de existencia necesaria y personas jurídicas de existencia posible ${ }^{3}$. Las personas de existencia necesaria se regulan por el derecho público y su existencia no depende de las normas del derecho privado. Las de existencia posible son, en la teoría de Savigny, aquéllas que crea la legislación de derecho privado ${ }^{4}$. En la doc-

${ }^{3}$ LLOVERAS DE RESK, María E., en Código Civil y normas complementarias. Análisis doctrinario y jurisprudencial, BUERES, Alberto J. (Dirección); HIGHTON, Elena I., (Coordinación), Hammurabi, Buenos Aires, 1995, p. 298/299.

${ }^{4}$ LAVALLE COBO, Jorge E. en Código Civil y leyes complentarias. Comentado, anotado y concordado, BELLUSCIO, Augusto C.

(Director), ZANNONI, Eduardo A. (Coordinador), Tomo 1, Astrea, Buenos Aires, 1978, p. 147 
trina y legislación modernas se abandonó este criterio, adoptando el establecido desde 1968.

De tal modo, las personas jurídicas públicas son aquéllas cuya existencia y funcionamiento dependen del Derecho Público, aunque parte de su actividad esté regulada por el Derecho Privado. Las personas jurídicas privadas son aquéllas que tienen reglamentada su existencia y actividades por el derecho privado aunque dependan de una autorización especial para funcionar.

La inclusión en el art. 145 de las personas jurídicas públicas se hace con un fin meramente descriptivo, ya que la personalidad de estas entidades resulta de las respectivas disposiciones de derecho público. En los Fundamentos del Anteproyecto se justifica la mención de las personas jurídicas públicas por la tradición que existe en el C.C. y porque en diversas partes del nuevo código se hace referencia a ellas, principalmente al Estado Nacional, las provincias y municipios.

\section{LAS PERSONAS JURÍDICAS PRIVADAS}

\section{VIII.1. El derecho de asociarse libremente y la atribución legal de personalidad}

La segunda clasificación que merece un análisis es la de la persona jurídica privada, que de acuerdo al art. 148 del CCC incluye, a modo enunciativo, a las siguientes:

a) las sociedades;

b) las asociaciones civiles;

c) las simples asociaciones;

d) las fundaciones;

e) las iglesias, confesiones, comunidades o entidades religiosas;

f) las mutuales;

g) las cooperativas;

h) el consorcio de propiedad horizontal;

i) toda otra contemplada en disposiciones de este Código o en otras leyes y cuyo carácter de tal se establece o resulta de su finalidad y normas de funcionamiento.

Con respeto a éste último inciso, se advierte una contradicción con el propósito expresado en los Fundamentos del Anteproyecto, en los cuales se hace mención a un numerus clausus de personas jurídicas privadas considerado suficiente para cubrir el derecho constitucional de asociarse libremente ${ }^{5}$.

Se mantiene el criterio de no reconocer personalidad jurídica a las agrupaciones de colaboración, a las uniones transitorias de empresas y a los consorcios de cooperación, que ahora se encuentran reguladas en el CCC en los arts. 1442 a 1478. 


\section{VIII.2. La participación del Estado no debiera cambiar el carácter de la persona}

Desde otro costado, una cuestión relevante importa la participación del Estado en las personas jurídicas privadas, que de conformidad al art. 149, aquella no modifica el carácter de éstas, sin embargo, la norma señala que: “...la ley o el estatuto pueden prever derechos y obligaciones diferenciados, considerando el interés público comprometido en dicha participación”.

De tal modo, no es una cuestión controvertida el hecho que el Estado pueda actuar como poder público y también en el derecho privado en pie de igualdad con los particulares. No obstante, corresponderá analizar en cada caso particular los alcances de la participación estatal cuando se convierta en entidad controlante de una empresa privada o directamente sea titular del total de su capital social, situación que puede derivar, inclusive, en una aplicación de los principios de la teoría del disregard, plasmada en el artículo 144 del CCC, con la consiguiente imputación directa al Estado de las obligaciones de la sociedad ${ }^{6}$.

Sin embargo, es destacable la manda del art. 149 pues viene a solucionar múltiples problemas de interpretación respecto del carácter de determinadas personas jurídicas.

En definitiva, la participación del Estado en una persona jurídica privada no transforma la calidad de ésta, la que sigue siendo privada sin importar el grado de participación del Estado y sin perjuicio de que se prevea un régimen especial en materia de derechos y obligaciones.

Además, corresponde advertir que la norma se aplica no sólo a las sociedades sino a todo tipo de personas jurídicas de carácter privado. La Ley 19.550 se ocupa de regular las sociedades anónimas con participación estatal mayoritaria creando un régimen especial para éstas, sin afectar su carácter privado, lo que armoniza con el art. 149 del CCC.

\section{LOS ATRIBUTOS DE LAS PERSONAS JURÍDICAS}

\section{IX.1. Nombre y domicilio}

Desde esta perspectiva, al igual que lo hace con la persona física, el CCC regula los atributos de la persona jurídica, los que nomina en: nombre, el domicilio y el patrimonio.

En primer lugar, el nombre se requiere a los fines de la identificación de la persona jurídica, y debe llevar el aditamento de la forma jurídica adoptada, tal como lo requiere el art. 151 del CCC. Además, la manda dispone que la persona jurídica en liquidación debe aclarar esta circunstancia en la utilización de su nombre.

En lo que hace al nombre o razón social, cabe observar que si bien se establece el principio de que el mismo "debe satisfacer recaudos de veracidad, novedad y aptitud distintiva, tanto respecto de otros nombres como de marcas, nombres de fantasía u otras formas de 
referencia a bienes o servicios", la disposición no contiene una solución superadora del actual inconveniente referido al modo de evitar los homónimos, en razón de la naturaleza federal de los registros y organismos de policía correspondientes, por lo que habrá que interpretar que, salvo las protecciones marcarias de los nombres, la prioridad estará dada por la fecha de constitución de las respectivas entidades?.

El segundo atributo de las personas jurídicas es el domicilio, cuya regulación se encuentra en el art. 152 del CCC, siguiendo en este aspecto lo reglado en el art. 11 inc. 2 de la ley General de Sociedades.

El texto del CCC puntualmente establece que: "El domicilio de la persona jurídica es el fijado en sus estatutos o en la autorización que se le dio para funcionar. La persona jurídica que posee muchos establecimientos o sucursales tiene su domicilio especial en el lugar de dichos establecimientos sólo para la ejecución de las obligaciones allí contraídas. El cambio de domicilio requiere modificación del estatuto. El cambio de sede, si no forma parte del estatuto, puede ser resuelto por el órgano de administración”.

\section{IX.2. Patrimonio y plazo de duración de las personas jurídicas}

En este sentido, la legislación también incorpora la exigencia del patrimonio de la entidad, habilitándose a la inscripción preventiva de bienes registrables, de conformidad a lo establecido en la ley societaria.

Así, la exigencia de un patrimonio responde al reconocimiento como persona, sujeto de derecho, y como parte constitutiva de su realidad subyacente.

El patrimonio constituye un elemento esencial de la persona jurídica. El art. 1 de la Ley 19.550 establece que habrá sociedad si una o más personas en forma organizada conforme a uno de los tipos previstos en esta ley, se obligan a realizar aportes para aplicarlos a la producción e intercambio de bienes y servicios. Así, el patrimonio comienza a formarse desde el mismo momento en que los socios se comprometen a realizar aportes. El patrimonio es el conjunto de bienes de la persona jurídica y se distingue del capital.

El valor del conjunto de los aportes constituye el capital social que se mantiene invariable mientras no se modifique el contrato. En cambio, el patrimonio social está formado por el conjunto de bienes del activo con el cual la sociedad actúa y afronta el pasivo que lo integra.

En cuanto a la inscripción de bienes registrables a nombre de la sociedad en formación, el artículo en comentario brinda una respuesta adecuada, teniendo presente que el párr. 2 del art. 187 de la Ley 19.550 impone que los aportes no dinerarios deben integrarse totalmente al constituirse la sociedad debiendo acreditarse su cumplimiento al momento de solicitar la inscripción.

${ }_{7}$ LAVALLE COBO, Jorge, "La Teoría General de las Personas Jurídicas", en Comentarios al Proyecto de Código Civil y Comercial de la Nación, RIVERA, Julio César (Director), Abeledo Perrot, Buenos Aires, 2012, p. 98-99. 
En cuarto lugar, el ordenamiento establece en el art. 155 que el plazo de duración de la persona jurídica es ilimitado, excepto que se disponga lo contrario en el estatuto.

Sin embargo, la ley General de Sociedades impone un plazo determinado a este tipo de persona jurídica, conforme al inc. 5 del art. 11, que mantiene la misma redacción. Este dispositivo determina que el estatuto debe indicar "el plazo de duración, que debe ser determinado".

En cuanto a las personas jurídicas privadas que no sean sociedades (asociaciones, fundaciones, mutuales y cooperativas), salvo disposición contraria del contrato social o estatuto, las mismas pueden tener una duración ilimitada en el tiempo. En el caso de las asociaciones civiles, el art. 170, inc. e), determina que la asociación puede constituirse a perpetuidad.

\section{X.EL OBJETO DE LAS PERSONAS JURÍDICAS}

Desde esta perspectiva, el artículo 156 establece que "debe ser preciso y determinado", es decir, limitado a las operaciones concretas que se desarrollarán, evitando las menciones genéricas de actividades, lo que es correcto, pero insuficiente, pues las finalidades para las cuales se personifican las instituciones deben ser de carácter lícito y de acuerdo con las reglas de la moral. Entendemos que la omisión se subsana por mantener vigencia los artículos 18 y 20 de la ley 19.550 que, respectivamente, prescriben la nulidad absoluta para las sociedades de objeto ilícito o prohibido por las leyes.

\section{EL GOBIERNO, ADMINISTRACIÓN Y FISCALIZACIÓN}

La organicidad de la persona jurídica está reconocida en el art. 158 del CCC, en cuanto establece que el estatuto debe contener normas sobre el gobierno, la administración y representación, y eventualmente la fiscalización.

Así, subsidiariamente ante falta de previsión convencional, rigen las siguientes reglas:

a) si todos los que deben participar del acto lo consienten, pueden participar en una asamblea o reunión del órgano de gobierno, utilizando medios que les permitan a los participantes comunicarse simultáneamente entre ellos. El acta debe ser suscripta por el presidente y otro administrador, indicándose la modalidad adoptada, debiendo guardarse las constancias, de acuerdo al medio utilizado para comunicarse;

b) los miembros que deban participar en una asamblea, o los integrantes del consejo, pueden autoconvocarse para deliberar, sin necesidad de citación pre- 
via. Las decisiones que se tomen son válidas, si concurren todos y el temario a tratar es aprobado por unanimidad".

El dispositivo contempla la totalidad de las personas jurídicas privadas admitidas por el CCC.

Así, puntualiza que los actos constitutivos de éstas deben contener normas sobre el gobierno del ente, tal como lo disponen el inc. 6 del art. 11 de la LGS para las sociedades; el inc. 4 del art. 8 de la Ley 20.337 para las cooperativas; el inc. f) del art. 6 de la Ley 20.321 para las mutuales; el inc. h) del art. 170 del CCC para las asociaciones civiles y, los inc. f) y g) del art. 195 del CCC para las fundaciones.

De este modo, sin perjuicio de la obligatoriedad para cada tipo de persona jurídica de incorporar a su estatuto o contrato social normas de administración y fiscalización, igual manda se incorpora como pauta general de las personas jurídicas.

En conclusión, el art. 158 del CCC establece de modo general la obligación de incluir en el estatuto normas sobre el gobierno, la administración, la representación y la fiscalización de las personas jurídicas; ésta última, en los supuestos en que sea una exigencia legal. Para el caso de silencio u omisión, el artículo prevé normas supletorias.

\section{EL DEBER DE LEALTAD Y DILIGENCIA DE LOS ADMINISTRADORES}

\section{XII.1. Las pautas de actuación}

Desde esta perspectiva, en los arts. 159, 160 y 161 del CCC, se incorporan las directivas que había elaborado la doctrina societarista, a los fines de otorgarle el carácter de reglas generales en torno al patrón de conducta de los administradores y su eventual responsabilidad.

Así, el art. 159 del CCC dispone con respecto a los administradores de la persona jurídica lo siguiente: "Deber de lealtad y diligencia. Interés contrario. Los administradores de la persona jurídica deben obrar con lealtad y diligencia.

No pueden perseguir ni favorecer intereses contrarios a los de la persona jurídica. Si en determinada operación los tuvieran por sí o por interpósita persona, deben hacerlo saber a los demás miembros del órgano de administración o en su caso al órgano de gobierno y abstenerse de cualquier intervención relacionada con dicha operación.

Les corresponde implementar sistemas y medios preventivos que reduzcan el riesgo de conflictos de intereses en sus relaciones con la persona jurídica”.

De tal modo, cabe aclarar que los administradores no son mandatarios sino órganos de la sociedad; son representantes de ésta que, en cuanto personas individuales, administran y gestionan bienes e intereses ajenos. En esa actividad de gestión deben ser leales con la persona 
que les encarga la función de administrar sus intereses, y obrar con diligencia, lo que se corresponde con las pautas de valoración de conducta establecida en los arts. 1724 y 1725 del CCC.

En consecuencia, estas directivas establecen un factor de atribución subjetivo, que debe ser ponderado de conformidad a cada tipo de persona jurídica, en función de la obligación de actuar con prudencia y pleno conocimiento.

\section{XII.2. El cartabón de conducta de los administradores societarios}

Por el contrario, en materia societaria, la pauta es diferenciada, tal como se sigue del art. 59 de la Ley General de Sociedades, que dispone que: "Los administradores y los representantes de la sociedad deben obrar con lealtad y con la diligencia de un buen hombre de negocios. Los que faltaren a sus obligaciones son responsables ilimitada y solidariamente, por los daños y perjuicios que resultasen de su acción u omisión”.

De tal modo, en el CCC se establece una pauta general a la cual debe adecuarse la conducta de los administradores sociales, cualquiera fuere el tipo social. Se trata de conductas no regladas por la ley, estatuto o reglamento social y que deben analizarse bajo el prisma de los standars de conducta del art. 59 de la Ley de Sociedades ${ }^{8}$.

En efecto, la Ley de Sociedades adoptó una pauta general y abstracta al imponer en el art. 59 un "obrar con la lealtad y la diligencia de un buen hombre de negocios”. Además, se ocupó de determinar normas específicas de conducta en los distintos tipos sociales, que constituyen la aplicación a los casos particulares de las pautas contenidas en el art. 59 de la Ley 19.550. Por su parte, el estatuto o el reglamento social también pueden regular detalladamente ciertos aspectos de la conducta de los administradores. En estos casos, se trata de conductas regladas por la ley, el estatuto o el reglamento.

El CCC deja de lado el cartabón del buen hombre de negocios, es decir, la de un comerciante experto. Esta pauta genérica establece una responsabilidad profesional ya que ella implica capacidad técnica, experiencia y conocimientos frente a la persona jurídica que administra. La diligencia del buen hombre de negocios exige la aptitud profesional necesaria para el exitoso desenvolvimiento de la clase de actividad que constituye el objeto social tomando como parámetro la aptitud que comúnmente se encuentra en personas que administran negocios de igual o parecida naturaleza.

En definitiva, el art. 159 del CCC no contiene una pauta abstracta, a diferencia del art. 59 de la Ley de Sociedades (buen hombre de negocios), sino que impone concretamente el deber de actuar con lealtad y diligencia a los administradores de las personas jurídicas privadas.

${ }^{8}$ ROITMAN, Horacio, Ley de Sociedades Comerciales. Comentada y anotada, Tomo I, La Ley, Buenos Aires, 2006, p. 882. 


\section{EL RÉGIMEN DE RESPONSABILIDAD: SOLIDARIA E ILIMITADA}

En este ámbito, relativo a la conducta de los administradores y los parámetros que deben respetar para una buena gestión, el art. 160 del CCC, siguiendo la normativa societaria, convierte en pauta general el régimen de responsabilidad.

Así, la norma establece que: "Los administradores responden en forma ilimitada y solidaria frente a la persona jurídica, sus miembros y terceros, por los daños causados por su culpa en el ejercicio o con ocasión de sus funciones, por acción u omisión”.

En esta inteligencia, se advierte que la obligación de los administradores es de medios y no de resultado, toda vez que solamente tienen el deber de poner la diligencia, lealtad y profesionalidad necesarias para lograr el objeto de la persona jurídica, que puede no llegar a concretarse, no por su mal desempeño sino -entre otros motivos- por adversa fortuna en los negocios?.

Por otro costado, los administradores responderán ilimitadamente con todo su patrimonio por los daños que produzcan a la persona jurídica y/o a terceros, con su acción u omisión, a sus miembros o a terceros, con su obrar desleal o negligente.

Desde esta perspectiva, se trata de la aplicación de los principios generales de la responsabilidad, arts. 1716 que impone el deber de reparar un daño a quien viole el deber de no dañar a otro, o que incumpla una obligación.

Además, se configura en la función de garantía establecida en el art. 242 y 743 de la nueva compilación, en orden a que el patrimonio de una persona es la prenda común de sus acreedores.

Asimismo, se establece que la responsabilidad será solidaria entre los administradores que faltaren a sus obligaciones de lealtad y diligencia en los casos de administración plural.

\section{LA PREVENCIÓN COMO PARÁMETRO DE CONDUCTA}

El artículo 161 del nuevo código establece el procedimiento legal para la superación de la oposición sistemática en el desempeño de las funciones del administrador, tal como hemos venido describiendo y que a los fines de una mayor claridad, cabe esquematizar del siguiente modo.

En primer lugar, el inciso a) autoriza al presidente o a cualquiera de los coadministradores a ejecutar los actos conservatorios.

El inciso b) obliga a poner los actos ejecutados en conocimiento de una asamblea convocada a ese efecto, convocar a la asamblea en el plazo de diez días de comenzada la ejecución de los actos en cuestión.

${ }^{9}$ OTAEGUI, Julio C., “Responsabilidad Civil de los Directores”, RDCO, 1978, Año 11, p. 1287. 
El inciso c) regula las medidas que puede adoptar la asamblea, las que consisten en: 1) conferir facultades extraordinarias al presidente o a la minoría para realizar actos urgentes o 2) remover al administrador.

La asamblea puede confirmar los actos conservatorios, modificar las facultades del órgano de administración, rechazar las medidas dispuestas por la minoría e incluso responsabilizar a ésta por los daños y perjuicios que pudieran haber ocasionado a la persona jurídica.

En definitiva, el art. 161 CCC tiene por finalidad evitar conflictos -a través de un mecanismo de solución de controversias- ante oposiciones automáticas que impidan adoptar decisiones válidas al órgano de administración.

Va de suyo que también se encuentra de por medio la posibilidad de que además de pedir la remoción del administrador renuente, la asamblea autorice al presidente a ejercer la acción preventiva reglada en el art. 1711 del Código Civil, sin perjuicio de que en el ámbito societario se pueda requerir la intervención como cautelar típica reglada en los arts. 113 a 116 de la LGS.

\section{LA VIABILIDAD DE LA TRANSFORMACIÓN}

El artículo 162 del CCC introduce de manera expresa la facultad de las personas jurídicas de transformarse, fusionarse y escindirse, cuestiones tratadas en la Ley 19.550 (arts. 74 a 88).

De tal modo, el CCC no deroga a la LGS sino que cambia su denominación por la de "Ley General de Sociedades” y modifica alguno de sus artículos, entre los cuales no se encuentran los antes citados.

La transformación consiste en el cambio de un tipo de persona jurídica por otro, mientras que la fusión hace referencia a la situación por medio de la cual dos o más personas jurídicas se disuelven sin liquidarse para constituir una nueva, o cuando una persona jurídica ya existente incorpora a otra u otras que, sin liquidarse, son disueltas.

El artículo 162 del CCC impone, para estas vicisitudes de las personas jurídicas, el voto afirmativo unánime de los miembros de la o las personas jurídicas, excepto disposición especial o estipulación en contrario del estatuto. Estos últimos supuestos se refieren a una mayoría inferior, puesto que no existe un voto afirmativo más exigente que la unanimidad.

En el caso de los consorcios de propiedad horizontal, reconocidos por el inciso h) del art. 148 del CCC, no existe norma que regule sobre la transformación, fusión y escisión de los mismos. El régimen de las asociaciones civiles incorporado en el nuevo código tampoco contiene normas sobre este tema, pero el art. 186 dispone que se aplican supletoriamente las disposiciones sobre sociedades, en lo pertinente. El art. 223 del CCC se ocupa del cambio de objeto, fusión y coordinación de actividades de las fundaciones. La Ley de Asociaciones Mutuales incorpora una norma sobre fusión en su art. 30. La ley 20.337 de Sociedades Cooperativas, 
además del art. 6 que prohíbe la transformación en sociedades comerciales o en asociaciones civiles, en su art. 58, al mencionar las competencias exclusivas de la asamblea, incorpora en su inciso 4, la fusión o incorporación.

\section{LA DISOLUCIÓN Y LIQUIDACIÓN}

Desde esta atalaya, nuevamente el ordenamiento unificado civil y comercial establece pautas generales en orden a la disolución y liquidación de la persona jurídica en el art. 163.

Las causales de disolución incorporadas son:

1) La declaración de quiebra, aclarando que la disolución queda sin efecto si la quiebra concluye por avenimiento o se dispone la conversión del trámite en concurso preventivo, o si la ley especial prevé un régimen distinto.

2) La fusión respecto de las personas jurídicas que se fusionan o personas jurídicas cuyo patrimonio es absorbido y la escisión respecto de la persona jurídica que se divide y destina todo su patrimonio.

3) La reducción a uno del número de miembros, si la ley especial exige pluralidad de ellos y ésta no es restablecida dentro de los tres meses.

4) La denegatoria o revocación firmes de la autorización estatal para funcionar, cuando ésta sea requerida.

5) Cualquier otra causa prevista en el estatuto o en otras disposiciones de este Título o de ley especial.

Va de suyo que el análisis de cada uno de éstos requeriría de un tratamiento integral que excede el presente trabajo.

\section{LA REVOCACIÓN DE LA AUTORIZACIÓN PARA FUNCIONAR}

La revocación de la autorización estatal está prevista en el art. 165 del CCC, en cuanto establece aquellos casos que la entidad requiere, por su actividad, de una autorización estatal para funcionar como tal, verbigracia: entidades financieras, entidades aseguradoras, etc.

Así, el dispositivo establece que el acto de autorización estatal debe ser revocado cuando se vulneran gravemente las condiciones en que fue otorgado.

Ello es así puesto que el acto administrativo de revocación implica en estos casos un juicio de la conducta de las personas jurídicas involucradas, y la decisión correspondiente debe constituir el proceder impuesto a quienes han transgredido las normas jurídicas. 
Lo novedoso es que, por un lado, se deja en claro qué resolución debe tomarse luego de realizado un procedimiento que garantice el derecho de defensa de la persona jurídica, y por el otro, que tratándose de una sanción que impone el Estado, el recurso judicial es de plena jurisdicción, y no queda limitado a la legitimidad o arbitrariedad de la decisión como estaba previsto en los arts. 45 y 48 del C.C. ${ }^{10}$.

\section{PRÓRROGA Y RECONDUCCIÓN}

Por su parte, el art. 165 del CCC se ocupa de la prórroga de la persona jurídica habilitando su viabilidad por decisión de sus miembros, antes del vencimiento del plazo, en una clara reiteración de lo que dispone el art. 95 de la LGS.

Por su parte, el art. 166 prevé la posibilidad de la reconducción de la persona jurídica, mientras no haya concluido su liquidación.

La norma señala que la decisión en tal sentido debe ser adoptada por unanimidad o la mayoría de sus miembros requerida por la ley o el estatuto, siempre que la causa de su disolución pueda quedar removida por decisión de los miembros o en virtud de la ley.

Mientras que la prórroga del funcionamiento de la persona jurídica determina la continuación normal del ente instrumentada para evitar la disolución, la reconducción es un remedio para revertir los efectos de la disolución ya operada.

\section{LIQUIDACIÓN Y RESPONSABILIDADES}

El C.C no contiene norma alguna relacionada con la liquidación de las personas jurídicas y la fuente del art. 167 se encuentra en el art. 162 del Proyecto del año 1998 y en los arts. 105 a 109 de la Ley 19.550.

Ante el acaecimiento de alguna causal de disolución la persona jurídica queda impedida de realizar nuevas operaciones, y su actividad se limita a la conclusión de aquellos actos que se encuentren pendientes al momento de declararse o producirse la disolución.

La liquidación consiste en el cumplimiento de las obligaciones pendientes con los bienes del activo del patrimonio de la persona jurídica o su producido en dinero (realización del activo y cancelación del pasivo).

${ }^{10}$ ALONSO, Juan Ignacio, GIATTI, Gustavo Javier, "Título II: Persona Jurídica. Capítulo 1: Parte General”, en Código Civil y Comercial de la Nación comentado, RIVERA, Julio César, MEDINA, Graciela (Directores), ESPER, Mariano (Coordinador), Tomo I, La Ley, Buenos Aires, 2014, p. 430 
El remanente de la liquidación será distribuido entre los miembros de la persona jurídica o entregado a terceros, según lo disponga el estatuto o lo exija la ley en el caso concreto.

Previo a ello, se deberán cancelar los gastos de la liquidación y la totalidad de las obligaciones fiscales pendientes.

Por último, se establece la responsabilidad solidaria e ilimitada en caso de infracción a lo dispuesto en el artículo, distinguiéndose entre: 1) Los administradores, quienes responden en términos generales como representantes legales del ente. 2) Los miembros, que sólo deben responder si conocían o debían conocer la situación que derivó en la infracción y que, contando con el poder de decisión necesario para ponerle fin, hayan omitido adoptar las medidas necesarias al efecto.

En definitiva, el art. 167 del CCC incorpora de manera resumida, la totalidad de las normas previstas en la Ley 19.550 para el caso de liquidación de una sociedad ${ }^{11}$.

\section{CONCLUSIÓN}

El legislador ha definido a la persona jurídica demarcándose el principio de separación diferenciada con respecto a sus miembros, quienes no responden por las obligaciones de éstas, excepto en la medida en que la ley lo disponga.

La fuerza jurígena de la voluntad de la creación de la persona jurídica privada conlleva que la personalidad nace con el acuerdo de voluntades de los miembros.

Se regla el sistema de responsabilidad de los administradores, en función de las pautas de lealtad y diligencia, dejándose a salvo la diferencia existente con el régimen de la Ley General de Sociedades, que a dichos parámetros los agrava con el cartabón del "buen hombre de negocios".

La normativa nada dice de las acciones advirtiéndose una ausencia de regulación que deberá ser cubierta con las normas contenidas en los arts. 276 a 279 de la LGS.

En efecto, no cabe duda que el daño que, eventualmente, pueda imputarse a los administradores, puede ser a título singular, por un tercero contratante con el ente social, como así también puede afectar a la propia persona, todo lo cual requerirá definir cuándo se está frente a una acción social y cuándo a una particular.

Se introduce la figura de la inoponibilidad de la persona jurídica, incorporada como pauta general, no es nada más ni nada menos que una aplicación concreta del abuso del derecho, pero que tal como lo establece el art. 54 ter de la LS, no implica la nulidad del negocio jurídico sino que es una alternativa de responsabilización de quienes habilitaron el uso "desviado" de la persona jurídica.

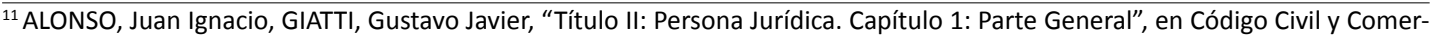
cial de la Nación comentado, RIVERA, Julio César, MEDINA, Graciela (Directores), ESPER, Mariano (Coordinador), Tomo I, La Ley, Buenos Aires, 2014, p. 433
} 
El nuevo Código también incluye otras regulaciones comunes a cualquier tipo de persona jurídica, como son sus atributos: nombre, domicilio, patrimonio y plazo de duración, como así también, las disposiciones relativas al gobierno, representación y fiscalización de dichos entes.

Por último, la teoría general de las personas jurídicas concluye reglando las causales de extinción y disolución, como así también las alternativas de prórroga y/o reconducción de aquellas, prescribiendo específicamente la responsabilidad de los administradores en los actos de liquidación.

En fin, la teoría general construida en el ámbito societario ha sido asumida por el Código Civil y Comercial.

\section{CURRICULUM VITAE}

\section{Francisco Junyent Bas}

Doctor Honoris Causa de la Universidad San Pablo Tucumán, con tesis sobre "La homologación judicial le otorga al convenio de mayorías el rango de concordato", según resolución Nº 463/20012. Doctor en Derecho y Ciencias Sociales de la Universidad Nacional de Córdoba, con tesis sobresaliente sobre Responsabilidad civil de los administradores societarios, 1995.

Profesor Titular Plenario de Derecho Concursal en la Universidad Nacional de Córdoba, desde 1996.

Profesor de Posgrado de diversas universidades del país.

Premio Academia Nacional de Derecho de Córdoba 1998.

Distinción académica "Ut portet nomen meun coram gentibus", Facultad de Derecho de la Universidad Nacional de Córdoba.

Autor de 25 libros de la especialidad, entre otros, La ley de Concursos comentada, El salvataje de las Entidades Deportivas, ley 25284, Facultades del Juez concursal y Sistema de Ineficacia concursal en coautoría con Carlos Molina Sandoval, Responsabilidad de Administradores Societarios, Responsabilidad de Terceros en la quiebra, Responsabilidad por Fraude Laboral, Las Relaciones laborales ante el concurso y la quiebra, Acuerdo Preventivo Extrajudicial en coautoría con Mauricio Boretto, El salvataje o Cramdown en la ley 25589 en coautoría con Eduardo Chiavassa, Sociedad y Empresa: Las reglas del buen gobierno, La tutela de la Vivienda única, entre otros. Autor de más de 300 artículos en diversas revistas especializadas.

Disertante en más de 350 Conferencias en diversas universidades e instituciones jurídicas. Ex Juez Concursal de la Ciudad de Córdoba a partir de 1984. Actual Fiscal de Cámara Civil y Comercial, a partir de 1989. 
Director del Instituto de Estudios de la Magistratura de la Asociación de Magistrados de Provincia de Córdoba.

Presidente Honorario de la Fundación para el Estudio del Derecho Concursal y la Empresa en Crisis, Pablo Van Nieuwenhove, Tucumán.

Ex Director del Departamento de Derecho Comercial Facultad de Derecho Universidad Nacional de Córdoba.

Profesor Honorario de la Universidad Aconcagua, Mendoza.

Director del Semanario Jurídico de Comercio y Justicia.

Investigador Categoría 1 por la CONEAU en el ámbito universitario.

fjunyentbas@gmail.com 